\title{
BISPHOSPHONATES AND IMPLANTS
}

\author{
Eva Goyal, Vivek Sharma ${ }^{2}$, Vineet Bhatia ${ }^{3}$, Jaspreet Singh Gill', Gagandeep Gupta ${ }^{5}$ \\ ${ }^{1}$ PG Student, Department of Periodontics, Desh Bhagat Dental College and Hospital, Punjab, India. \\ ${ }^{2}$ Professor, Department of Periodontics, Desh Bhagat Dental College and Hospital, Punjab, India \\ ${ }^{3}$ Professor, Department of Periodontics, Desh Bhagat Dental College and Hospital, Punjab, India \\ ${ }^{4}$ Associate professor, Department of Periodontics, Desh Bhagat Dental College and Hospital, Punjab, India \\ ${ }^{5}$ Assistant professor, Department of Periodontics, Desh Bhagat Dental College and Hospital, Punjab, India
}

Corresponding Author:

Eva Goyal

E-mail: dreva12@gmail.com

Received: $15^{\text {th }}$ January 2017

Accepted: $23^{\text {rd }}$ April 2017

Online: $20^{\text {th }}$ May 2017

\begin{abstract}
The posterior portion of the maxilla has been described as the most difficult part of the mouth for the implant practitioner, and it requires great ability to achieve successful results. Anatomical considerations include reduced bone quantity, especially in patients who have had alveolar resorption in the wake of tooth loss. So, it may be necessary to perform a bone augmentation procedure before placing the implant. However, one disadvantage of using autogenous bone is the unpredictable bone resorption, which might be reduced by the use of bisphosphonates, perhaps locally. Bisphosphonates have been tested for treating osteoporosis and they are in clinical use. These drugs can also be used to reduce peri-implant resorption thereby allowing orthopedic implants to achieve a stronger primary fixation. Once released from the surface of a coated implant, bisphosphonates reduce osteoclast activity, thereby changing the balance of bone turnover, leading to a net increase in local bone density. Clinically, this idea has been tested in orthopedics but not in dentistry. For dental implants, improved fixation would enable surgeons to push the limits regarding the quality of bone (in a surgical sense) in which implants can be inserted.
\end{abstract}

Keywords - Bisphosphonates, Bone Augmentation, Peri-implant Resorption, Osteoclast

\section{INTRODUCTION}

Throughout history, humans have sought ways to replace lost teeth. However, it is only within the past 100 years that members of the dental and medical professions have made substantial progress in the permanent replacement of missing teeth by intraosseous anchorage of artificial metal fixtures. Fifty years later, the term osseointegration was coined by Brånemark. It is defined as the direct contact between living bone tissue and implants that can lead to biological adhesion. Osseointegration is observed in several areas, not only with dental implants, but also with maxillofacial implants, replacement of damaged joints, and placement of artificial limbs. The success of these operations is dependent of the fixation of the implants, which, in turn, depends on the strength of the bone that holds them. If bone quality is poor, surgical procedures can be modified to provide sufficient mechanical fixation by adding more screws or larger devices, or by protecting the implant from mechanical loading for a considerable time after surgery, for osseointegration. Thus, if the quality of the bone holding an implant could be improved locally, surgical procedures would become simpler and rehabilitation would become faster. In patients with alveolar resorption, it may be required to perform bone augmentation before placing implants which may cause unpredictable resorption of bone, which might be reduced by the use of bisphosphonates.

Bisphosphonates are anti-resorptive drugs that act specifically on osteoclasts, thereby maintaining bone density and strength. ${ }^{1}$ They are potent osteoclast inhibitors and are considered the drug of choice for the treatment of diseases affecting bone metabolism. During the last decades, the stability of implants with local bisphosphonate treatment has been 
tested in clinical studies ${ }^{2}$ and animal studies, ${ }^{3-7}$ but not in human jaws.

\section{STRUCTURE AND BIOACTIVITY OF BISPHOSPHONATES}

Bisphosphonates were introduced in the mid1990 s as an alternative to hormone replacement therapies for treatment of osteoporosis. In 1996 Fosamax ${ }^{\circledR}$ (alendronate, marketed by Merck) was the first bisphosphonate drug approved in the U.S. for the treatment of osteoporosis.

Bisphosphonates are used in many clinical settings, including prevention and treatment of primary and secondary osteoporosis, Paget's disease of bone, hypercalcemia, multiple myeloma and osteolysis associated with bone metastases of malignant tumors8. They may directly inhibit the bone-resorbing activity of osteoclasts by mechanisms that can lead to osteoclast apoptosis9. Moreover, a study by Sahni et al. suggested that part of the inhibitory action of bisphosphonates on the osteoclasts is mediated through an action on the osteoblasts. ${ }^{10}$

Bisphosphonates also directly promote the proliferation and differentiation of human osteoblastlike cells in vitro. ${ }^{11}$ It has been reported that these drugs cause a number of effects on other cells, including inhibition of cell proliferation ${ }^{12}$ and causing a decrease in cell adhesion, in fibroblasts ${ }^{13}$ and in macrophages. ${ }^{14-15}$

Bisphosphonates are synthetic pyrophosphate analogs with a P-C-P bond instead of the P-O-P bond of inorganic pyrophosphates, which are used as anti-tarter agents in toothpastes and as a bone-specific radionuclide in technetium $99 \mathrm{~m}$ methylene diphosphonate (Tc 99m MDP) bone scans.

Unlike pyrophosphates, bisphosphonates are resistant to breakdown by enzymatic hydrolysis, which explains their accumulation in the bone matrix and their extremely long half-life16. The P-C-P structure (Figure 1) allows a great number of possible variations, especially by changing the two lateral chains (R1 and $\mathrm{R} 2$ ) in the carbon atom. The two phosphate groups are essential for binding to bone mineral such as hydroxyapatite and together with the $\mathrm{R} 1$ side chain they act as a "bone hook". A hydroxyl $(\mathrm{OH})$ group or an amino group at the R1 position increases the affinity for calcium and thus for bone mineral. ${ }^{17-18}$

\section{MECHANISMS OF ACTION OF}

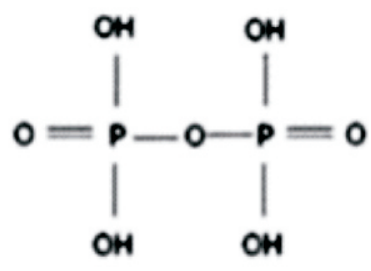

Pyrophosphate

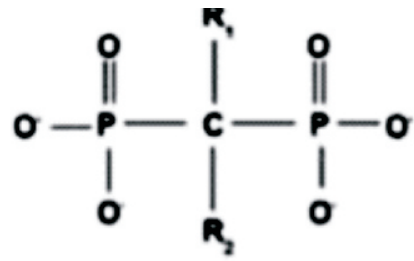

Bisphosphonate
Figure 1 - Pyrophosphate and bisphosphonate structures

\section{BISPHOSPHONATES}

The mechanisms of action of bisphosphonates in bone metabolism are complex. They are believed to act on bone through several mechanisms simultaneously. The reduction in osteoclastic activity occurs as a result of internalization of bisphosphonates by the osteoclasts, causing disruption of bone resorption. ${ }^{19-21}$ The decrease in osteoclast numbers is the result of the inhibition of osteoclast recruitment and acceleration of programmed cell death/apoptosis. ${ }^{22-23}$ Both of these mechanisms lead to a reduction of bone resorption and a decrease in bone turnover.

According to Gutta and Louis, ${ }^{24}$ there are seven proposed mechanism of action of bisphosphonates

1. The first generation bisphosphonates, such as clodronate and etidronate, do not contain an amino group. They are metabolized to form cytotoxic adenosine triphosphate (ATP) analogs that accumulate intra-cellularly in osteoclasts and induce apoptosis.

2. The potent amino bisphosphonates are inhibitors of the mevalonate pathway, a biosynthetic pathway for isoprenoid proteins such as farnesyl diphosphate and geranyl diphosphate. The isoprenoid proteins are required for posttranslational prenylation of the small GTPases such as RAS, Rho, and Rac. The Rho and Rac groups of proteins are responsible for cytoskeletal organization and cell membrane ruffling and are activated through geranylgeranylation. The cytoskeleton is essential to maintain the "ruffled border", the area with which the osteoclast makes contact with bone and breaks down bone tissue. With the ruffled border compromised, the osteoclast initiates apoptosis, resulting in a decrease in bone turnover. 
3. Bisphosphonates also inhibit various matrix metalloproteinases involved in cancer growth and metastasis.

4. Although bisphosphonates are also known to have antiangiogenic effects, there has been some controversy based on histological reports of osteonecrotic samples.

5. There are some reports that bisphosphonates may inhibit bone resorption by stimulating osteoblasts to produce an osteoclast-inhibitory factor.

6. Bisphosphonates are also reported to be powerful inhibitors of macrophage proliferation, cells that are of the same lineage as osteoclasts.

7. Other mechanisms include inhibition of osteoclast proton ATPase, phosphatases, and other lysosomal enzymes

\section{IMPLANTS AND COATING TECHNIQUE}

It has been hypothesized that a bisphosphonate coating improves the fixation of dental implants. The coating technique for dental implants was presented by Tengvall et al. ${ }^{25}$ Briefly, a cross linked layer of fibrinogen was covalently bound to the metal, and then small amounts of pamidronate and ibandronate were bound and adsorbed to the fibrinogen matrix. In an animal model, the thickness of this bisphosphonate layer (a few $\mathrm{nm}$ ) was measured by ellipsometry. Ellipsometry is an optical method that is often used to measure the thickness of thin films adsorbed to flat surfaces. However, because the surface area of the screw is much greater than a corresponding flat surface, it may be difficult to translate the amount of drug on a flat surface to that of the screw.

The recommended human dose of alendronate for treatment of osteoporosis is $10 \mathrm{mg} /$ day. The gastrointestinal uptake of oral bisphosphonates is about $0.7 \%$ for alendronate ${ }^{26}$ and $0.3 \%$ for pamidronate. ${ }^{27}$ For individuals weighing $75 \mathrm{~kg}$, this means that of the prescribed human daily dose of bisphosphonates, approximately $0.5-1 \mu \mathrm{g} / \mathrm{kg} /$ day reaches the bloodstream. For comparison, the total amount of bisphosphonate on coated human dental implants is in the order of $1 \mu \mathrm{g}$ ibandronate (less than $1 \mu \mathrm{g} / \mathrm{cm} 2$ ). Clinically, osteoporosis patients are given ibandronate as an oral dose of $50 \mathrm{mg}$ per day for individuals weighing $60 \mathrm{~kg}(\sim 833 \mu \mathrm{g} / \mathrm{kg}))^{28}$ Thus, the amount of bisphosphonate on the surface of the dental implant corresponds to the total body dose of one day of osteoporosis treatment.

After insertion of bisphosphonate-coated implants, the bisphosphonate is released from the surface and rapidly accumulates in the surrounding bone tissues. In an animal model using a fibrinogen immobilization matrix and $14 \mathrm{C}$-alendronate, $60 \%$ of the immobilized bisphosphonate was released after $8 \mathrm{~h}$, but the release continued slowly for up to 8 days. ${ }^{3}$ Once released from the surface of a coated implant, bisphosphonates reduce osteoclast activity, thereby changing the balance of bone turnover in favor of bone formation, leading to a net gain in local bone density. ${ }^{28}$ Fast formation of a shell of new woven bone surrounding the implant is seen, which becomes slowly remodeled into lamellar bone. ${ }^{29}$ Furthermore, it has been shown that the amount of bone increases adjacent to the implant with a maximum density $250 \mu \mathrm{m}$ from the implant surface. ${ }^{30}$ Given that bisphosphonates significantly reduce bone turnover, there is a possibility that patients taking bisphosphonates may have problems with integration occurring during the osteoconductive phase or, if the implants are already successfully integrated, the reduced bone remodeling and bone turnover may result in a potential for loss of integration. ${ }^{31}$

\section{POSITIVE EFFECTS OF BISPHOSPHONATES ON DENTAL IMPLANT TREATMENT}

Extensive research undertaken by Abtahi et al. ${ }^{32}$ investigated whether a bisphosphonate coating could be beneficial to implant osseointegration. During the last decades, the stability of implants with local bisphosphonate treatment has been tested in clinical studies and animal studies, but not in human jaws. Abtahi et al. ${ }^{32}$ showed that a bisphosphonate coating improved the fixation of dental implants in humans. They carried out a randomized double-blind study, in which fibrinogen-coated dental implants with immobilized pamidronate and ibandronate were inserted into the maxilla. The implant stability was determined by resonance frequency analysis (RFA) 
and implant stability quotant (ISQ) readings. Resonance-frequency analysis is a reliable and noninvasive method to measure the quality of fixation in humans. Radiographic appearances were improved when compared to a control group. The theory behind this positive effect is that once bisphosphonates are released from the surface of the coated implant, there is a localized reduction in osteoclastic activity, altering the balance of bone turnover in favor of increased osteoblastic activity, leading to increased bone formation which in turn increases the local bone density. ${ }^{32-33}$ This improved early fixation may reduce the rate of late implant failures and could also allow earlier loading times.

\section{LONG TERM EFFECTS OF BISPHOSPHONATES}

\section{Bisphosphonates related osteonecrosis of the jaw (BRONJ)}

This condition of the jaw is defined as non-healing, exposed bone for more than 8 weeks in patients receiving a bisphosphonate and without any history of local radiation therapy. ${ }^{34-35}$ Clinically, the disease presents as exposed alveolar bone that occurs spontaneously or becomes evident following a surgical procedure such as tooth removal, periodontal surgery, apicoectom can be placed in patients receiving oral bisphosphonates for the treatment of osteoporosis. ${ }^{45}$

\section{Staging and treatment strategies}

A clinical staging system has been developed in order to more accurately categorize patients with ONJ (Table 1).

In early stages, surgical debridement and coverage has been successful. Segmental osteotomies are recommended only for severe cases. ${ }^{45-47}$ However, this controversial treatment has a high morbidity and affects the quality of life of patients. ${ }^{48}$ The difficulty in treating ONJ has highlighted the importance of prevention. Before starting on bisphosphonate therapy, patients should be screened for dental comorbidities and invasive dental procedures should be performed.

\begin{tabular}{|c|c|}
\hline BRONJ Staging & Treatment Strategies \\
\hline $\begin{array}{l}\text { At risk category } \\
\text { No apparent necrotic bone in } \\
\text { patients who have been treated } \\
\text { with either oral or IV } \\
\text { bisphosphonates }\end{array}$ & $\begin{array}{l}\text { - No treatment indicated } \\
\text { - Patient education }\end{array}$ \\
\hline $\begin{array}{l}\text { Stage } 0 \\
\text { No clinical evidence of necrotic } \\
\text { bone, but non-specific clinical } \\
\text { findings and Symptoms }\end{array}$ & $\begin{array}{l}\text { - Systemic management } \\
\text { - Medications and } \\
\text { antibiotics }\end{array}$ \\
\hline $\begin{array}{l}\text { Stage } 1 \\
\text { Exposed and necrotic bone in } \\
\text { patients who are asymptomatic } \\
\text { and have no evidence of } \\
\text { infection }\end{array}$ & $\begin{array}{l}\text { - Antibacterial mouth } \\
\text { rinse } \\
\text { - Clinical follow-up on a } \\
\text { quarterly basis } \\
\text { - Patient education and } \\
\text { review of indications for } \\
\text { continued } \\
\text { bisphosphonate therapy }\end{array}$ \\
\hline $\begin{array}{l}\text { Stage } 2 \\
\text { Exposed and necrotic bone } \\
\text { associated with infection as } \\
\text { evidenced by pain and } \\
\text { erythema in the region of the } \\
\text { exposed bone with or without } \\
\text { purulent drainage }\end{array}$ & $\begin{array}{l}\text { - Symptomatic treatment } \\
\text { with oral antibiotics } \\
\text { - Oral antibacterial } \\
\text { mouth rinse } \\
\text { - Pain control } \\
\text { - Superficial debridement } \\
\text { to relieve soft tissue } \\
\text { irritating. }\end{array}$ \\
\hline $\begin{array}{l}\text { Stage } 3 \\
\text { Exposed and necrotic bone in } \\
\text { patients with pain, infection, } \\
\text { and one or more of the } \\
\text { following: exposed and necrotic } \\
\text { bone extending beyond the } \\
\text { region of alveolar bone, (i.e., } \\
\text { inferior border and ramus in the } \\
\text { mandible, maxillary sinus and } \\
\text { zygoma in the maxilla) } \\
\text { resulting in pathologic fracture, } \\
\text { extra-oral fistula, oral antral/ } \\
\text { oral nasal communication, or } \\
\text { osteolysis extending to the } \\
\text { inferior border of the mandible } \\
\text { of sinus floor }\end{array}$ & $\begin{array}{l}\text { - Antibacterial mouth } \\
\text { rinse } \\
\text { - Antibiotic therapy and } \\
\text { pain control } \\
\text { - Surgical } \\
\text { debridement/resection } \\
\text { for longer term palliation } \\
\text { of infection }\end{array}$ \\
\hline
\end{tabular}

Table 1. Clinical staging of BRONJ and treatment strategies according to the American Association of Oral and Maxillofacial Surgeons (AAOMS).

\section{Prevention}

There are currently no evidence-based guidelines on the management of bisphosphonate- induced ONJ; therefore, emphasis is placed on preventive measures.

Before the start of bisphosphonate therapy, the patient should be referred for a thorough dental evaluation to identify and treat any potential sources of infection. The dentist should emphasize oral hygiene instructions and routine dental prophylaxis to ensure 
optimal dental health. If dental health is suboptimal and tooth extraction is required, bisphosphonate therapy should be delayed by 4-6 weeks to allow appropriate bone healing. ${ }^{49}$ If a patient is already on bisphosphonate therapy with no evidence of osteonecrosis, it is paramount to emphasize good oral hygiene and preventive dental care.

\section{Direct toxicity to oral mucosal cells}

The direct toxic effects of bisphosphonates on oral mucosa can result in the ability of oral pathogens to pass through defective or severely damaged oral mucosa and infect the bone. ${ }^{50}$ Clinically, gastrointestinal intolerability is one of the most recognizable side effects of oral preparations of nitrogen-containing bisphosphonates such as alendronate, risendronate and ibandronate. Indeed, they can cause oesophageal ulceration if they do not reach the stomach quick enough. While some authors believe that bisphosphonate toxicity to gastrointestinal cells is the result of inhibition of farnesyl pyrophosphate synthase (FPPS) in the mevalonate pathway, ${ }^{51}$ it is generally believed that a compromised integrity of the mucosal epithelium alone is not enough to allow uninterrupted access to the bone surface and that a local immune response must also be compromised. It has been postulated that the acidity of local tissue (reduced $\mathrm{pH}$ ) is altered by changes in the oral mucosa, periodontal disease, ill-fitting dentures, or dental surgery, thereby increasing the release of bisphosphonates to rise to potentially toxic levels. ${ }^{52,53}$ These effects are believed to depress bone remodeling of the jaws and therefore impair wound healing.

\section{CONCLUSION}

Local treatment of implants with bisphosphonate may have a future place in orthopedic surgery and dental surgery, since bisphosphonate coatings improved the fixation of dental implants in the human jaw. However, the clinical benefits of this technique are still not understood. One could speculate that if bisphosphonates have an effect in the early phase of healing, then rehabilitation after implantation would become faster. An important issue is the risk that patients might be exposed to with the use of locally delivered bisphosphonates. A potential risk would be the peri-implantitis, which may jeopardize the entire perception of local bisphosphonate treatment. More short and long term data are needed to fully evaluate the benefits of bisphosphonates in implant surgery.

\section{REFERENCES}

1. S.-J.H.S. Qui, G. Gibson, K. Lundin-Cannon, M. Schaffler. Osteocyte apoptosis After Acute Matrix Injury in Compact Bone. The Orthopaedic Research Society, San Francisco 1997.

2. Hilding M, Ryd L, Toksvig-Larsen S, Aspenberg P. Clodronate prevents prosthetic migration: a randomized radiostereometric study of 50 total knee patients. Acta Orthop Scand 2000;71:553-557.

3. Wermelin $\mathrm{K}$, Aspenberg $\mathrm{P}$, Linderbäck $\mathrm{P}$, Tengvall $\mathrm{P}$. Bisphosphonate coating on titanium screws increases mechanical fixation in rat tibia after two weeks. J Biomed Mater Res A. 2008;86: 220-7.

4. M. Yoshinari, Y. Oda, T. Inoue, K. Matsuzaka, M. Shimono. Bone response to calcium phosphate-coated and bisphosphonate-immobilized titanium implants. Biomaterials. 2002;14:2879-85.

5. Peter B, Gauthier O, Laïb S, Bujoli B, Guicheux J, Janvier P, van Lenthe GH, Müller R, Zambelli PY, Bouler JM, Pioletti DP. Local delivery of bisphosphonate from coated orthopedic implants increases implants mechanical stability in osteoporotic rats. J Biomed Mater Res A 2006;76:133-43.

6. Roshan-Ghias A, Arnoldi J, Procter P, Pioletti DP. In vivo assessment of local effects after application of bone screws delivering bisphosphonates into a compromised cancellous bone site. Clin Biomech. 2011; 26: 1039-43.

7. Stadelmann VA, Gauthier O, Terrier A, Bouler JM, Pioletti DP. Implants delivering bisphosphonate locally increase periprosthetic bone density in an osteoporotic sheep model. A pilot study. Eur Cell Mater.2008; 31: 10-6.

8. Rogers MJ, Watts DJ, Russell RG (1997) Overview of bisphosphonates. Cancer 80: 1652-1660.

9. Holen I, Coleman RE. Bisphosphonates as treatment of bone metastases. Curr Pharm Des 16: 262-7 2010. Hughes DE, Wright KR, Uy HL, Sasaki A, Yoneda T, Roodman GD, Mundy GR, Boyce BF. Bisphosphonates promote apoptosis in murine osteoclasts in vitro and in vivo. J Bone Miner Res. 1995; 10: 1478-87.

10. Sahni M, Guenther HL, Fleisch H, Collin P, Martin TJ. Bisphosphonates act on rat bone resorption through the mediation of osteoblasts. J Clin Invest. 1993; 91: 2004-11.

11. Im GI, Qureshi SA, Kenney J, Rubash HE, Shanbhag AS. 
Osteoblast proliferation and maturation by bisphosphonates. Biomaterials 2004; 25: 4105-15.

12. Rogers MJ. New insights into the molecular mechanisms of actions of bisphosphonates. Curr Pharm 2003; 9: 2643-58.

13. Fast DK, Felix R, Dowse C, Neuman WF, Fleisch H. The effects of diphosphonates on the growth and glycolysis of connective-tissue cells in culture. Biochem J .1978; 15: 97107.

14. Cecchini MG, Felix R, Fleisch H, Cooper PH. Effect of bisphosphonates on proliferation and viability of mouse bone marrow derived macrophages. J Bone Miner Res. 1987; 2: 135-42.

15. Reitsma PH, Teitelbaum SL, Bijvoet OL, Kahn AJ. Differential action of the bisphosphonates (3-amino-1hydroxypropylidene)-1,1-bisphosphonate (APD) and disodium dichloromethylidene bisphosphonate (C12MDP) on rat macrophage-mediated bone resorption in vitro. J Clin Invest. 1982; 70: 927-33.

16. Cremers SC, Pillai G, Papapoulos SE. Pharmacokinetics/ pharmacodynamics of bisphosphonates: use for optimisation of intermittent therapy for osteoporosis. Clin Pharmacokinet. $2005 ; 44: 551-70$.

17. van Beek ER, Löwik CW, Ebetino FH, Papapoulos SE. Binding and antiresorptive properties of heterocyclecontaining bisphosphonate analogs: structure-activity relationships. Bone 1998; 23: 437-42.

18. Russell RG, Xia Z, Dunford JE, Oppermann U, Kwaasi A, Hulley PA, Kavanagh KL, Triffitt JT, Lundy MW, Phipps RJ, Barnett BL, Coxon FP, Rogers MJ, Watts NB, Ebetino FH. Bisphosphonates: an update on mechanisms of action and how these relate to clinical efficacy. Ann N YAcad Sci 2007; 11: 209-57.

19. Madrid C, Sanz M. What impact do systemically administrated bisphosphonates have on oral implant therapy? A systematic review. Clin Oral Implants Res. 2009; 20 (4): 8795.

20. Coxon FP, Thompson K, Rogers MJ .Recent advances in understanding the mechanism of action of bisphosphonates. Curr Opin Pharmacol. 2006; 6: 307-312.

21. Russell RG. Bisphosphonates: mode of action and pharmacology. Pediatrics. 2007; 119 (2): 150-162.

22. Bayliss L, Mahoney DJ, Monk, P. Normal bone physiology, remodeling and its hormonal regulation. Surgery. 2012 ; 30(2): 47-53

23. Walia M, Arora S, Singal B. Oral Bisphosphonates and Dental Implants: A Review and Update. J Impl Adv Clin Dent. 2011; 3(1): 83-87.
24. Gutta R, Louis PJ. Bisphosphonates and osteonecrosis of the jaws: science and rationale. Oral Surg Oral Med Oral Pathol Oral Radiol Endod. 2007;104:186-193.

25. Tengvall P, Skoglund B, Askendal A, Aspenberg P. Surface immobilized bisphosphonate improves stainless-steel screw fixation in rats. Biomaterials. $2004 ; 25: 2133-8$.

26. Gertz BJ, Holland SD, Kline WF, Matuszewski BK, Porras AG. Clinical pharmacology of alendronate sodium. Osteoporos Int. 1993;3:13-6.

27. Daley-Yates PT, Dodwell DJ, Pongchaidecha M, Coleman RE, Howell A. The clearance and bioavailability of pamidronate in patients with breast cancer and bone metastases. CalcifTissue Int 1991; 49: 433-5.

28. Devitt B, McLachlan SA. Use of ibandronate in the prevention of skeletal events in metastatic breast cancer. Ther Clin Risk Manag 2008; 4: 453-58.

29. Bobyn JD, McKenzie K, Karabasz D, Krygier JJ, Tanzer M. Locally delivered bisphosphonate for enhancement of bone formation and implant fixation. J Bone Joint Surg Am 2009; 6: 23-31.

30. Wermelin K, Suska F, Tengvall P, Thomsen P, Aspenberg P. Stainless steel screws coated with bisphosphonates gave stronger fixation and more surrounding bone. Histomorphometry in rats. Bone. 2008; 42: 365-71.

31. Goss A, Bartold M, Sambrook P, Hawker P. The nature and frequency of bisphosphonate-associated osteonecrosis of the jaws in dental implant patients: a South Australian case series. J Oral Maxillofac Surg. 2010; 68: 337-343

32. Abtahi J, Tengvall P, Aspenberg P. A bisphosphonate-coating improves the fixation. J Dent Res of metal implants in human bone. A randomized trial of dental implants. Bone 2012; 50: 1148-1151.

33. Berardi D, Carlesi T, Rossi F, Calderini M, Volpi R. Potential applications of biphosphonates in dental surgical implants. Int J Immuno pathol Pharmacol 2007; 20: 455-465.

34. Khosla S, Burr D, Cauley J, Dempster DW, Ebeling PR, Felsenberg D. Bisphosphonate-associated osteonecrosis of the jaw: report of a task force of the American Society for Bone and Mineral Research. American Society for Bone and Mineral Research 2007; 22: 1479-91.

35. American Association of Oral and Maxillofacial Surgeons positionpaper on bisphosphonate-related osteonecrosis of the jaws. Advisory Task Force on Bisphosphonate-Related Ostenonecrosis of the Jaws, American Association of Oral and Maxillofacial Surgeons. Source AAOMS, Rosemont IL 60018, USA 2007; 65:369-76. 
36. Marx RE, Sawatari Y, Fortin M, Broumand V. Bisphosphonate-induced exposed bone (osteonecrosis/osteopetrosis) of the jaws: risk factors, recognition, prevention, and treatment. J Oral Maxillofac Surg 63: $1567-75$

37. Ruggiero SL, Mehrotra B, Rosenberg TJ, Engroff SL.Osteonecrosis of the jaws associated with the use of bisphosphonates: a review of 63 cases. J Oral Maxillofac Surg. 2004; 62: 527-34

38. Barasch A, Cunha-Cruz J, Curro FA, Hujoel P, Sung AH, Vena D, Voinea-Griffin AE. Risk factors for osteonecrosis of the jaws: a case-control study from the CONDOR dental PBRN 2011; 90: 439-44.

39. Vescovi P, Campisi G, Fusco V, Mergoni G, Manfredi M, et al. Surgerytriggered and non surgery-triggered Bisphosphonaterelated Osteonecrosis of the Jaws (BRONJ): A retrospective analysis of 567 cases in an Italian multicenter study. Oral Oncol 2011; 191-4.

40. Vescovi P, Merigo E, Meleti M, Manfredi M, Guidotti R. Bisphosphonates-related osteonecrosis of the jaws: a concise review of the literature and a report of a single-centre experience with 151 patients. J Oral Pathol Med 2012; 41: 214-221.

41. Vescovi P, Nammour S. Bisphosphonate-Related Osteonecrosis of theJaw (BRONJ) therapy. A critical review. Minerva Stomatol. 2010; 59: 181-203 204-13.

42. Allen MR. The effects of bisphosphonates on jaw bone remodeling, tissue properties, and extraction healing. Odontology 2011;99: 8-17.

43. Palaska PK, Cartsos V, Zavras AI. Bisphosphonates and time to osteonecrosis development. Oncologist .2009;14: 1154-66.

44. Rutkowski JL. Combined use of glucocorticoids and bisphosphonates may increase severity of bisphosphonaterelated osteonecrosis of the jaw. J Oral Implantol 2011;
37:505.

45. Carlson ER, Basile JD. The role of surgical resection in the management of bisphosphonate-related osteonecrosis of the jaws. J Oral Maxillofac Surg 2009; 67: 85-95.

46. Mucke T, Koschinski J, Deppe H, Wagenpfeil S, Pautke C, Mitchell DA, Wolff KD, Holzle F. Outcome of treatment and parameters influencing recurrence in patients with bisphosphonate-related osteonecrosis of the jaws. J Cancer Res Clin Oncol. 2010; 137: 907-13.

47. Seth R, Futran ND, Alam DS, Knott PD. Outcomes of vascularized bone graft reconstruction of the mandible in bisphosphonate-related osteonecrosis of the jaws. Laryngoscope.2010; 120:2165-71.

48. Filleul O, Crompot E, Saussez S. Bisphosphonate-induced osteonecrosis of the jaw: a review of 2,400 patient cases. J Cancer Res Clin Oncol. 2010; 136: 1117-24.

49. Ruggiero SL, Fantasia J, Carlson E. Bisphosphonaterelatedosteonecrosis of the jaw: background and guidelines for diagnosis, staging and management. Oral Surg Oral Med Oral Pathol Oral Radiol Endod. 2006; 102: 433-41.

50. Pazianas M. Osteonecrosis of the jaw and the role of macrophages. J Natl Cancer Inst. 2011;103: 232-240.

51. Reszka AA, Rodan GA. Nitrogen-containing bisphosphonate mechanism of action. Mini Rev Med Chem. 2004; 4: 711-719.

52. Allen MR, Burr DB. Bisphosphonate effects on bone turnover, microdamage, and mechanical properties: what we think we know and what we know that we don't know. Bone 2011; 49: 56-65.

53. Otto S, Schreyer C, Hafner S, Mast G, Ehrenfeld M. Bisphosphonate related osteonecrosis of the jaws characteristics, risk factors, clinical features, localization and impact on oncological treatment. J Craniomaxillofac Surg. 2012; 40:303-309. 